\title{
Meta-analysis of effect of vernakalant on conversion of atrial fibrillation
}

\author{
He Yan, Thi Thi Aung, Zhong Guogiang, Zhang Zhengnan, Ji Lan and Zeng Zhiyu*
}

\begin{abstract}
Background: In recent years, there has been a large amount of studies about the efficacy and safety of vernakalant or RSD1235, an antiarrhythmic agent, in treating the atrial fibrillation (AF). This study was designed to assess the efficacy and safety of vernakalant in the treatment of AF.

Results: A total of 5 randomized controlled trials $(R C T s)(n=1153)$ met our inclusion criteria. Vernakalant was superior in achieving sinus rhythm (SR) for AF comparing to placebo or alternative anti-arrhythmic agents (relative risk $[\mathrm{RR}]=11.56,95 \%$ Confidence Interval $[\mathrm{Cl}]=7.12-18.75$ ). There was no heterogeneity among the trials $\left(X^{2}=0.59, P=0.96\right)$. In analysing the adverse effects of cardiac origin, there was no significant difference between the two groups $(\mathrm{RR}=0.90,95 \% \mathrm{Cl}=0.52-1.57)$.

Methods: The Cochrane library, Pubmed NCBI, EMBASE and MEDLINE were systematically searched to identify all interventional trials of vernakalant with placebo or other antiarrhythmic drug in converting AF to SR. The primary outcome was rate of converting to SR, and the secondary outcome was the rate of adverse effects of cardiac origin due to vernakalant and the placebo or amiodarone. Meta-analyses were carried out using Mantel-Haenszel fixed-effects or random-effects models and heterogeneity was by the $X^{2}$ test.

Conclusion: In the conversion of AF to SR, vernakalant is highly effective without obviously raised side effects. Owing to only one study comparing vernakalant with amiodarone included in this study, the efficacy of vernakalant comparing to other antiarrhythmic agents needing more well-designed double-blinded RCTs to be confirmed.
\end{abstract}

Keywords: Vernakalant, Atrial fibrillation, Sinus rhythm, Conversion rate, Meta-analysis

\section{Background}

Atrial fibrillation (AF) is the most common sustained arrhythmia in population [1,2], and has association with significant morbidity and mortality. AF is highly associated with 5-fold increased risk of thromboembolic strokeand 2-fold increased risk of death than the general population [3,4]. Most patients with AF do not have significant hemodynamic instability and as such, pharmacological therapy is usually the initial treatment of choice.

Currently available antiarrhythmic drugs have modest efficacy in converting atrial fibrillation (AF) to sinus rhythm (SR). Because of the pro-arrhthmic potential of presently used anti-arrhythmic agents, there is an unmet need for a more safe and effective drug that will control arrhythmias. Vernakalant is a novel antiarrhythmic drug,

\footnotetext{
* Correspondence: zhiyuzeng@163.com

Department of Cardiology, The First Affiliated Hospital of Guangxi Medical University, Guangxi province, China
}

(c) 2013 Yan et al.; licensee BioMed Central Ltd. This is an Open Access article distributed under the terms of the Creative Commons Attribution License (http://creativecommons.org/licenses/by/2.0), which permits unrestricted use, distribution, and reproduction in any medium, provided the original work is properly cited. a sodium and ultra-rapid potassium channels blocker, prolonging atrial refractory periods and rate dependently show atrial conduction and has limited actions on ventricles $[5,6]$. It is available in both oral and intravenous forms. Phase III clinical trials of the intravenous formation and early Phase II studies of the oral formulation demonstrated vernakalant to be efficatious and safe in converting AF to SR. In patients with recent onset AF, vernakalant has been shown to be effective in rapid achieving and maintaining SR (51.2\% to $51.7 \%)[7,8]$ in some studies. In the FDA briefing documents, it was stated that vernakalant could also provide rapid recovery of atrial fibrillation-related symptoms as such palpitations, breathlessness, chest tightness/pain, dizziness and fatigue. Vernakalant was well tolerated in atrial fibrillation patients and the treatment-related adverse effects (AEs) most commonly occurred within the first 2 hours 
in patients receiving vernakalant while the most occurring ones were dysgeusia, sneezing and paraesthesia.

We pooled the data extracted from the included studies that compared vernakalant with placebo or amiodarone in conversion of AF to SR to gain sufficient power to evaluate the potential differences in efficacy and safety.

\section{Method}

\section{Literature search}

We searched Pubmed NCBI, EMBASE, MEDLINE and the Cochrane library with language restrictions to English for original research articles, systematic reviews and metaanalyses to identify all available literature on vernakalant and atrial fibrillation. We combined search terms for atrial fibrillation with vernakalant or RSD1235.

Inclusion criteria required each study to be randomized controlled trial comparing intravenous infusion of vernakalant with placebo or an alternative antiarrhythmic drug to treat $\mathrm{AF}$ including recent onset of $\mathrm{AF}$, paroxysmal $\mathrm{AF}$. We excluded non-randomized studies, those involving children or animals and also trials that evaluated the prophylactic use of vernakalant to prevent rather than to treat AF. This meta-analysis followed through The Preferred Reporting Items for Systematic Reviews and MetaAnalyses: The PRISMA Statement [9].

\section{Data extraction}

One author performed the literature search, and data extraction was independently conducted by two individuals. The following information was extracted: publication details, timing of study, duration of follow-up, randomization method, blinding (of participants, investigators, and outcome assessors), vernakalant dosage and route of administration, dropouts, mean age of participants, primary outcome (conversion rate to sinus rhythm) and secondary outcome (adverse events of cardiac origin). Any disagreements in the collected data was elucidated by consensus or, if necessary, upon consultation with a third reviewer. The authors of the original publications were contacted to obtain missing data.

Quality assessment of the individual trials was performed using Jadad scale [10] (range from 0 to 5, with the higher scales indicating a better quality trial). The grading of allocation concealment was according to the Cochrane approach, that is, adequate or uncertain or clearly inadequate. Data were checked and entered into the Review Manager 5 for Windows.

\section{Outcomes of interest}

The proportion of patients with atrial fibrillation converted to sinus rhythm within different duration of treatment was chosen as the primary outcome because it is the most relevant clinical outcome in patients with AF. And the occurrences of adverse events between vernakalant and the control groups were also assessed. There was no missing data for the main outcomes in the trials included.

\section{Statistical analysis}

The differences in categorical outcomes between vernakalant and placebo or an alternative antiarrhythmic drug were reported as risk ratio (RR) with 95\% confidence interval (CI), using a fixed effect model. The differences in adverse effects of cardiac origin between vernakalant and control groups were assessed by RR with 95\% CI using a random effect model. The presence of heterogeneity between trials was assessed by the $\mathrm{X}^{2}$ statistics and the extent of inconsistency was assessed using $\mathrm{I}^{2}$ statistics. All tests were two-tailed with a P value of less than 0.05 as the level of statistical significance.

\section{Results}

\section{Study selection and description}

Our electronic searches identified 80 studies of which 5 articles [7,8,11-13] fulfilled our inclusion criteria and were subjected to meta-analysis (Figure 1). The 5 included trials were published in english. There was complete

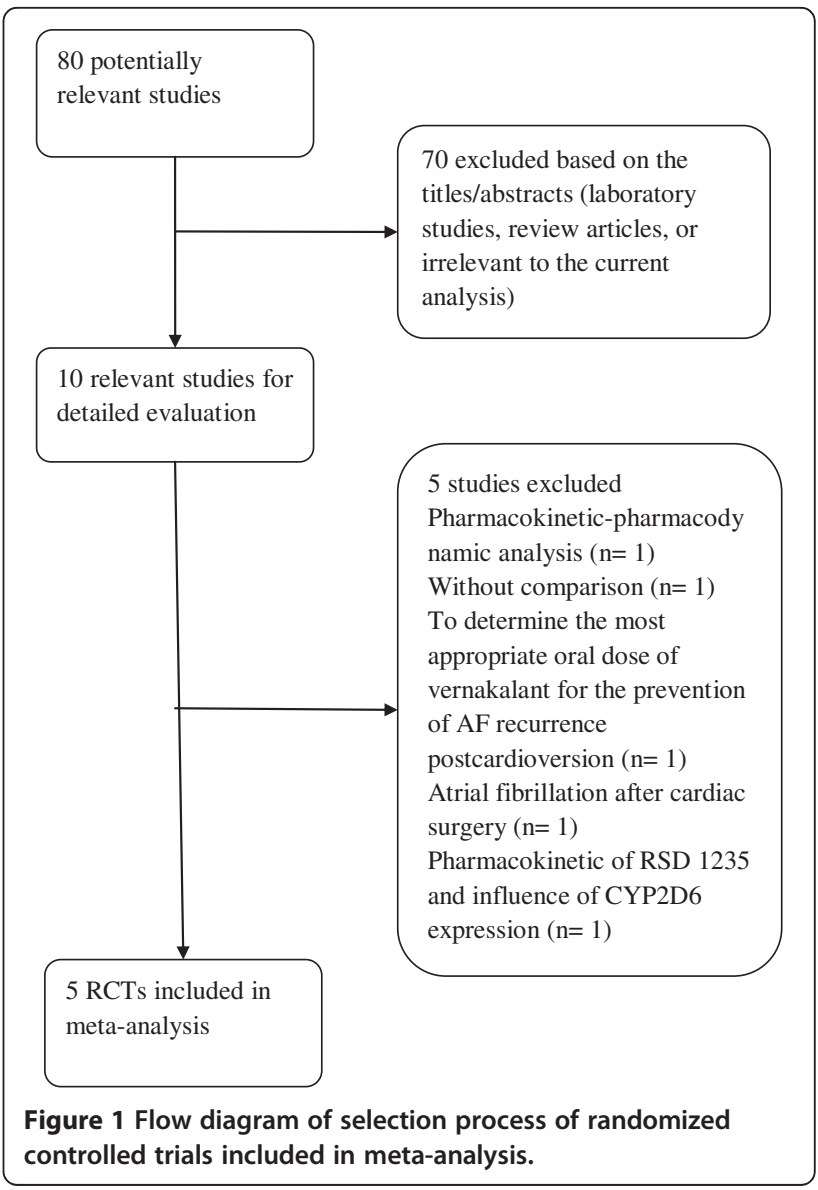


agreement on inclusion assessment between the three reviewers. Table 1 showed the characteristics of the 5 included trials. Four trials $[7,8,12,13]$ compared vernakalant with placebo and the remaining one [11] was with amiodarone.

The doses of intravenous vernakalant used ranged from $0.5 \mathrm{mg} / \mathrm{kg}$ to $3 \mathrm{mg} / \mathrm{kg}$. The time period assessed for the selected clinical end point of vernakalant treatment ranged between 30-min after last infusion to 90-min of drug initiation.

\section{Assessment of validity}

The quality of the included trials varied; the Jadad scale [10] ranged from 1 to 4 (mean 3). All trials were randomized but there was one trial which was not doubleblinded. The proportion of patients lost or excluded was

Table 1 General characteristics of included studies

\begin{tabular}{|c|c|c|c|c|c|c|c|c|c|}
\hline \multirow[t]{2}{*}{ Study } & \multirow[t]{2}{*}{$\mathrm{N}$} & \multicolumn{2}{|l|}{ Treatment groups } & \multirow[b]{2}{*}{$\begin{array}{l}\text { Goal follow-up } \\
\text { time }\end{array}$} & \multirow[b]{2}{*}{$\begin{array}{l}\text { Atrial fibrillation } \\
\text { time }\end{array}$} & \multicolumn{2}{|c|}{$\begin{array}{l}\text { Subject } \\
\text { characteristics }\end{array}$} & \multicolumn{2}{|c|}{$\begin{array}{l}\text { No. with } \\
\text { conversion }\end{array}$} \\
\hline & & Regimen & $\mathbf{n}$ & & & Age (Years) & Men (\%) & $\mathrm{n} / \mathrm{N}$ & $\%$ \\
\hline \multirow[t]{6}{*}{ Camm 2011} & 232 & Vernakalant & 116 & 1 week & AF 3 to 48 & 63 & 63 & $60 / 116$ & $51.7 \%$ \\
\hline & & $3 \mathrm{mg} / \mathrm{kg} \mid \mathrm{VI} \mathrm{f} / \mathrm{b}$ & & & hrs & & & & \\
\hline & & $2 \mathrm{mg} / \mathrm{kg}$ if & & & & & & & \\
\hline & & required $15 \mathrm{~min}$ & & & & & & & \\
\hline & & later & & & & & & $6 / 116$ & $5.2 \%$ \\
\hline & & $\begin{array}{l}\text { Amiodarone } 5 \mathrm{mg} / \mathrm{kg} \\
60 \text {-min IVI f/b } 50 \mathrm{mg} \text { IVI } \\
\text { over additional } 60 \mathrm{~min}\end{array}$ & 116 & & & & & & \\
\hline \multirow[t]{6}{*}{ Pratt 2010} & 239 & Vernakalant & 118 & 30 days & AF 3 hrs to & 63 & 65 & $47 / 118$ & $40 \%$ \\
\hline & & $3 \mathrm{mg} / \mathrm{kg} \mid \mathrm{VI} \mathrm{f} / \mathrm{b}$ & & & 45 days & & & & \\
\hline & & $2 \mathrm{mg} / \mathrm{kg}$ if & & & & & & & \\
\hline & & required $15 \mathrm{~min}$ & & & & & & $4 / 121$ & $3 \%$ \\
\hline & & later & & & & & & & \\
\hline & & Placebo & 121 & & & & & & \\
\hline \multirow[t]{7}{*}{ Roy 2004} & 56 & Vernakalant & 18 & 1 week & AF 3 to 72 & 64 & 61 & $2 / 18$ & $11 \%$ \\
\hline & & $0.5 \mathrm{mg} / \mathrm{kg} \mathrm{IVI} \mathrm{f/b}$ & & & hrs & & & & \\
\hline & & $1.0 \mathrm{mg} / \mathrm{kg}$ if & & & & & & & \\
\hline & & required $30 \mathrm{~min}$ & 18 & & & & & $11 / 18$ & $61 \%$ \\
\hline & & later & & & & & & & \\
\hline & & Vernakalant & & & & & & & \\
\hline & & $\begin{array}{l}2.0 \mathrm{mg} / \mathrm{kg} \mathrm{IVI} \mathrm{f/b} 3.0 \mathrm{mg} / \mathrm{kg} \\
\text { if required } 30 \text { min later } \\
\text { Placebo }\end{array}$ & 20 & & & & & $1 / 20$ & $5 \%$ \\
\hline \multirow[t]{6}{*}{ Roy 2008} & 336 & Vernakalant & 221 & 30 days & AF 3 hrs & 62 & 69 & $83 / 221$ & $37.6 \%$ \\
\hline & & $3 \mathrm{mg} / \mathrm{kg} \mid \mathrm{VI} \mathrm{f} / \mathrm{b}$ & & & to 45 days & & & & \\
\hline & & $2 \mathrm{mg} / \mathrm{kg}$ if & & & & & & & \\
\hline & & required $15 \mathrm{~min}$ & & & & & & & \\
\hline & & later & & & & & & $3 / 115$ & $2.6 \%$ \\
\hline & & Placebo & 115 & & & & & & \\
\hline \multirow[t]{5}{*}{ Stiell 2010} & 290 & Vernakalant & 229 & & AF 3 to 48 & & 69 & $136 / 229$ & $59.4 \%$ \\
\hline & & $3 \mathrm{mg} / \mathrm{kg} \mid \mathrm{VI} \mathrm{f} / \mathrm{b}$ & & & hrs & & & & \\
\hline & & $\begin{array}{l}2 \mathrm{mg} / \mathrm{kg} \text { if } \\
\text { required } 15 \mathrm{~min}\end{array}$ & & 1 week & & 59 & & & \\
\hline & & later & 61 & & & & & $3 / 61$ & $4.9 \%$ \\
\hline & & Placebo & & & & & & & \\
\hline
\end{tabular}


Table 2 Adverse effects

\begin{tabular}{llll}
\hline Study name & T/C & Adverse events & \\
\cline { 3 - 4 } & & Type & T/C \\
\hline Camm 2011 [11] & $116 / 116$ & Monomorphic nonsustained & $1 / 0$ \\
& & ventricular tachycardia & \\
& & Cardiac arrest & $0 / 1$ \\
Pratt 2010 [7] & $118 / 121$ & Ventricular tachycardia & $16 / 13$ \\
& & Ventricular fibrillation & $1 / 0$ \\
& & Bradycardia & $8 / 0$ \\
Roy 2004 [12] & \multirow{2}{*}{ 36/20 } & Cardiac disorders & $7 / 2$ \\
Roy 2008 [8] & $221 / 115$ & Nonsustained ventricular tachycardia & $14 / 17$ \\
& & Bradycardia & $1 / 0$ \\
& & Hypotension & $14 / 4$ \\
& & Ventricular bigeminy & $1 / 0$ \\
& & Uncorrected QT > 550 ms & $1 / 1$ \\
Stiell 2010 [13] & 229/61 & Any ventricular arrhythmia events & $20 / 10$ \\
& & Ventricular tachycardia & $18 / 9$ \\
& & Ventricular extrasystoles & $2 / 1$ \\
& & Bradycardia & $21 / 7$ \\
& & Hypotension & $20 / 7$ \\
\hline
\end{tabular}

less than $10 \%$ in all the included trials. The agreement between reviewers was over $90 \%$ for different criteria.

\section{Effect of intravenous vernakalant on rhythm conversion}

Five trials involving 1153 patients reported data on the effect of intravenous vernakalant on rhythm conversion. The relative risk (RR) of vernakalant on conversion rate of AF to SR was 11.56 (95\% confidence interval [CI] 7.12 to $18.75 ; \mathrm{p}<0.00001$ ) (Figure 2). Figure 2 depicts the RRs and $95 \% \mathrm{CI}$ for conversion to SR with vernakalant compared with control treatments for each of the 5 studies and 1 pooled RR.

\section{Adverse effects of cardiac origin}

All five trials included in this study showed adverse events (AEs) of cardiac origin. There was heterogeneity among the AEs of these studies $\left(\mathrm{I}^{2}=71 \%\right)$, and thus with random effect model, the RR of vernakalant on AEs of cardiac origin was $0.90(95 \% \mathrm{CI}=0.52$ to $1.57 ; \mathrm{p}=0.72)$ (Figure 3).

\section{Sensitivity analyses}

A series of sensitivity analyses was done to confirm the same directionality for the efficacy end point (conversion to SR) and the safety end point (adverse events of cardiac origin). There was no individual study affected the overall results for both efficacy and safety end points.

\section{Discussion}

This meta-analysis assessed the efficacy and safety of vernakalant on conversion of AF to SR. Vernakalant is associated with a stastically significant success in conversion of AF to SR. In this meta-analysis, vernakalant was superior to placebo and amiodarone in converting AF to $\mathrm{SR}$, but there was no difference in adverse effects of cardiac origin between the two groups.

There was one trial [13] with low quality had included into our analysis, obtaining 1 point in the Jadad scale. This study was not excluded because that paper was a post hoc analysis of ACT I and ACT IV in which ACT I was double-blind while the later was open-label. The remaining 4 trials had Jadad scale of 3 [7] and 4 $[8,11,12]$ respectively. The meta-analysis of vernakalant efficacy as compared with placebo or amiodarone revealed no heterogeneity $\left(\mathrm{I}^{2}=0 \%\right)$ while there was significant heterogeneity in comparison of AEs of cardiac origin between the two groups $\left(\mathrm{I}^{2}=71 \%\right)$. This may be mainly due to low incidence of AEs of cardiac origin in one trial [11] and the differences of follow-up time ranging from 1 week to 30 days.

The result of this meta-analysis is in accordance with previous reviews $[14,15]$ showing vernakalant is superior to placebo and amiodarone. It is needed to state that the conversion rates with vernakalant were lower in the AVRO [11] trial than those in a post hoc analysis [13] of data from ACT I and ACT IV in 3-48 hours' duration AF patients ( $51.7 \%$ vs $59 \%$ ) which may be caused by the different medical history, having a higher propotion of

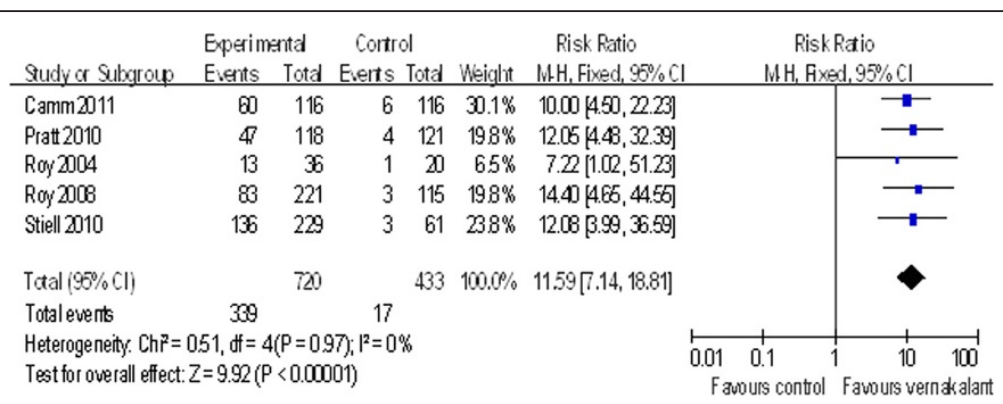

Figure 2 Forest Plot of the Risk Ratio of vernakalant on conversion rate of AF to SR. 
patients with CHF included in the AVRO trial (20\%) than later study $(5 \%)[11,13]$. Vernakalant is also superior in achieving SR in patients with post-operative AF enrolled in ACT II as compared with placebo (47\% vs $14 \%)$ [16]. The highest efficacy of vernakalant cardioversion rate was observed for AF up to 72 hours (70-80\%) [14] while it was relatively ineffective in AF patients with duration more than 7 days and in atrial flutter, having conversion rates of $8 \%$ and $2.5 \%$ respectively in ACT I and 9 and 7\% respectively in ACT III. Promising results were also obtained by evaluating an oral formulation of vernakalant for the maintenance of SR in phase II, placeo-controlled, dose-ranging studies $(300 \mathrm{mg}$ or $600 \mathrm{mg}$ twice daily) [17]. Vernakalant could achieve rapid termination of $\mathrm{AF}$ with median conversion time ranging from $8 \mathrm{~min}$ to $12 \mathrm{~min}$ while the median conversion time in control groups was much longer over $30 \mathrm{~min}$ to over $100 \mathrm{~min}$.

This meta-analysis showed no significant difference in occurring of AEs of cardiac origin between the two arms. The AEs other than cardiac origin was not extracted and analysed due to the presence of patients reporting more than one adverse event. According the trials, the most common drug-related adverse events occurring within the first 24 hours were dysgeusia, sneezing, paraesthesia and cough. Common cardiac disorders resulted in vernakalant groups included bradycardia and atrial flutter. The previous one responded well to discontinuation of vernakalant and/or intravenous atropine while the later was converted to SR with continuation of the infusion of vernakalant. Vernakalant is generally well tolerated in conversion of AF to SR with no significant QTc prolongation and proarrhythmia with the use of this drug have not been reported to date.

\section{Limitations of this study}

This study has some limitations. As our paper aimed to include only English full-text articles published in peerreviewed journals, there is a potential for publication bias. The number of included studies was too low to perform publication bias assessment using funnel plot or other widely accepted statistical methods. However, we can expect that studies excluded from the analysis were small and of low quality. As low-quality studies comprised less than $2 \%$ of the whole patient population included into the meta-analysis, the potential effect of lacking studies should be very low. Our study showed that vernakalant is superior to control group and since there was only one study comparing with amiodarone was included in this meta-analysis, further research comparing vernakalant and other antiarrhythmic agents through direct head-to-head comparisons may be needed to confirm this effect. There was no difference shown in safety outcome in this study between the vernakalant and control groups, however, more randomized controlled trials with a longer follow-up are needed to better evaluate the efficacy and safety of vernakalant on atrial fibrillation patients.

\section{Conclusions}

Vernakalant is effective and relatively rapid acting in converting AF to SR in a wide range of patients. Intravenous Vernakalant when compared to other antiarrhythmic agents is effective in converting AF to SR and may be used as first-line therapy in patients with AF.

Competing interests

The authors declare that they have no competing interests.

\section{Authors' contributions}

All authors were equally contributed. All authors read and approved the final manuscript.

Received: 7 January 2013 Accepted: 16 January 2013 Published: 13 March 2013

\section{References}

1. van den Berg MP, van Gelder IC, van Veldhuisen DJ: Impact of atrial fibrillation on mortality in patients with chronic heart failure. Eur J Heart Fail 2002, 4(5):571-575.

2. Wolf PA, Mitchell JB, Baker CS, Kannel WB, D'Agostino RB: Impact of atrial fibrillation on mortality, stroke, and medical costs. Arch Intern Med 1998, 158(3):229.

3. Kannel WB, Wolf PA, Benjamin EJ, Levy D: Prevalence, incidence, prognosis, and predisposing conditions for atrial fibrillation: populationbased estimates. Am J Cardiol 1998, 82(7):2N-9N.

4. Ruigómez A, Johansson S, Wallander MA, Rodríguez LG: Risk of mortality in a cohort of patients newly diagnosed with chronic atrial fibrillation. BMC Cardiovasc Disord 2002, 2(1):5. 
5. Dorian P, Pinter A, Mangat I, Korley V, Cvitkovic SS, Beatch GN: The effect of vernakalant (RSD1235), an investigational antiarrhythmic agent, on atrial electrophysiology in humans. J Cardiovasc Pharmacol 2007, 50(1):35.

6. Fedida D, Orth PMR, Hesketh JC, EZRIN AM: The role of late INa and antiarrhythmic drugs in EAD formation and termination in Purkinje fibers. J Cardiovasc Electrophysiol 2006, 17:S71-S78.

7. Pratt CM, Roy D, Torp-Pedersen C, Wyse DG, Toft E, Juul-Moller S, Retyk E, Drenning DH: Usefulness of vernakalant hydrochloride injection for rapid conversion of atrial fibrillation. Am J Cardiol 2010, 106(9):1277-1283.

8. Roy D, Pratt CM, Torp-Pedersen C, Wyse DG, Toft E, Juul-Moller S, Nielsen T, Rasmussen SL, Stiell IG, Coutu B, et al: Vernakalant hydrochloride for rapid conversion of atrial fibrillation: a phase 3 , randomized, placebocontrolled trial. Circulation 2008, 117(12):1518-1525.

9. Liberati A, Altman DG, Tetzlaff J, Mulrow C, Gøtzsche PC, loannidis J, Clarke M, Devereaux P, Kleijnen J, Moher D: The PRISMA statement for reporting systematic reviews and meta-analyses of studies that evaluate health care interventions: explanation and elaboration. J Clin Epidemiol 2009, 62(10):e1-e34.

10. Jadad AR, Moore RA, Carroll D, Jenkinson C, Reynolds DJM, Gavaghan DJ, McQuay HJ: Assessing the quality of reports of randomized clinical trials: is blinding necessary? Control Clin Trials 1996, 17(1):1-12.

11. Camm AJ, Capucci A, Hohnloser SH, Torp-Pedersen C, Van Gelder IC, Mangal B, Beatch G: A randomized active-controlled study comparing the efficacy and safety of vernakalant to amiodarone in recent-onset atrial fibrillation. J Am Coll Cardiol 2011, 57(3):313-321.

12. Roy D, Rowe BH, Stiell IG, Coutu B, Ip JH, Phaneuf D, Lee J, Vidaillet $H$, Dickinson G, Grant S, et al: A randomized, controlled trial of RSD1235, a novel anti-arrhythmic agent, in the treatment of recent onset atrial fibrillation. J Am Coll Cardiol 2004, 44(12):2355-2361.

13. Stiell IG, Dickinson G, Butterfield NN, Clement CM, Perry JJ, Vaillancourt C, Calder LA: Vernakalant hydrochloride: A novel atrial-selective agent for the cardioversion of recent-onset atrial fibrillation in the emergency department. Acad Emerg Med 2010, 17(11):1175-1182.

14. Savelieva I, Camm J: Anti-arrhythmic drug therapy for atrial fibrillation: current anti-arrhythmic drugs, investigational agents, and innovative approaches. Europace 2008, 10(6):647-665.

15. Kalus JS: Pharmacologic management of atrial fibrillation: established and emerging options. J Manag Care Pharm 2009, 15(6):S10-18.

16. Kowey P, Roy D, Pratt C, Schwartz P, Dorian P, Mitchell L, Toft E: Efficacy and safety of vernakalant hydrochloride injection for the treatment of atrial fibrillation after valvular or coronary artery bypass surgery. Circulation 2007, 116:7

17. Cheng JW: Vernakalant in the management of atrial fibrillation. Ann Pharmacother 2008, 42(4):533-542.

doi:10.1186/1756-0500-6-94

Cite this article as: Yan et al:: Meta-analysis of effect of vernakalant on conversion of atrial fibrillation. BMC Research Notes 2013 6:94.

\section{Submit your next manuscript to BioMed Central and take full advantage of:}

- Convenient online submission

- Thorough peer review

- No space constraints or color figure charges

- Immediate publication on acceptance

- Inclusion in PubMed, CAS, Scopus and Google Scholar

- Research which is freely available for redistribution

Submit your manuscript at www.biomedcentral.com/submit
C Biomed Central 